\title{
Lipid Status and Linear Relationship Between Total Cholesterol and Triglycerides in Glycogen Storage Disease Type la
}

\author{
Zhenjie Zhang \\ Peking Union Medical College Hospital \\ Yuheng Yuan \\ Heidelberg University \\ Mingsheng Ma \\ Peking Union Medical College Hospital \\ Yuehui Hong \\ Peking Union Medical College Hospital \\ Zhixing Sun \\ Peking Union Medical College Hospital \\ Yiwen Xu \\ Peking Union Medical College Hospital \\ Zhengqing Qiu ( $\nabla$ qiuzq@pumch.cn ) \\ Peking Union Medical College Hospital
}

Research

Keywords: Glycogen storage disease type la, lipid metabolism, atorvastatin

Posted Date: July 22nd, 2020

DOI: https://doi.org/10.21203/rs.3.rs-46912/v1

License: (c) (i) This work is licensed under a Creative Commons Attribution 4.0 International License. Read Full License 


\section{Abstract \\ Background}

Glycogen storage disease type la(GSDla) is a glucose metabolic disorder disease. GSDla patients are characterized by hypoglycemia, hepatomegaly, hyperlipidemia, and hyperlactacidemia. This study aims to review the lipid status, explore lipid treatment targets, and assess preferable lipid-lowering drugs.

\section{Methods}

Clinical data on GSDla patients' characteristics were collected. Diet control and raw cornstarch treatment were used to maintain normal blood glucose and lipid level. Some patients were given lipid-lowering drugs. We compared the lipid levels before and after each treatment.

\section{Results}

A total of $163 \mathrm{GSDla}$ patients were enrolled in this study. The lipid level was assessed 773 times. After treatment with raw cornstarch, TG level has significantly decreased by $30 \pm 50 \%(P<0.001)$. There was no change in TC level. Thirty patients regularly took atorvastatin or fibrates for more than one year. The therapeutic effect of atorvastatin was better than fibrates. The total cholesterol(TC) was positively correlated with TG after treatment, resulting in the following regression equation: $\mathrm{TG}=1.63^{*} \mathrm{TC}-2.86$.

\section{Conclusion}

Patients with GSDla have significant abnormalities in blood lipid metabolism. We found that there was a linear correlation between TC and TG, which was TG $=1.63^{*} \mathrm{TC}-2.86$. Because the complications of hyperlipidemia are caused mainly by TC, thereby, as long as the TC remains normal, we could set a TG target to allow a certain degree of hypertriglyceridemia. The bound of Chinese Children's TC normal level (5.18 mmol/L) was used in the established regression equation to obtain TG $=5.58 \mathrm{mmol} / \mathrm{L}$. We, therefore, targeted to keep TG level below $5.58 \mathrm{mmol} / \mathrm{L}$. This study found that the therapeutic effect of atorvastatin was better than fibrates.

\section{Background}

Glycogen storage disease type 1 (GSDI, OMIM 232200) is a glucose metabolic disorder caused by glucose-6-phosphatase (G6Pase) deficiency. The incidence of GSDI is about 1/100 000[1], of which GSDla accounts for $80 \%[2]$. Because the last step of glycogenolysis and gluconeogenesis is affected, GSDI patients present with severe hypoglycemia. Besides, patients also present with hyperlipidemia, hyperuricemia, hyperlactacidemia, and growth and development retardation[3]. The main therapeutic approaches are dietary control and raw cornstarch treatment. Raw cornstarch can maintain a normal glucose production rate, thus avoiding hypoglycemia and reducing secondary metabolic complications.

G6Pase is mainly located in the liver. It is composed of glucose-6-phosphatase catalytic subunit (G6PC) and glucose-6-phosphate transporter(G6PT)[4]. G6PC hydrolyzes G6P into glucose and phosphate. The G6PC active site is located in the endoplasmic reticulum, into which G6P is transported by G6PT[5][6]. Mutations in G6PC are the cause of GSDla.

Untreated GSDla patients usually show significant lipid metabolism disorder, which includes elevated triglyceride(TG) and total cholesterol(TC),and decreased low- and high-density lipoprotein-cholesterol(LDL-C and HDL-C, respectively)[7]. Although hyperlipidemia in GSDla patients is prevalent and severe, studies on lipid status in GSDla patients are extremely rare. Most reported studies are case reports, ignoring treatment status and genotyping. Currently, there is neither recommendation for lipid-lowering drugs nor definite treatment targets for GSDla patients.

To date, this is the most extensive retrospective single-center study of lipid metabolism in GSDla patients. In this study, we reviewed the status of lipid metabolism in GSDla patients, aiming to reveal their lipid status, explore the lipid treatment targets, and identify preferable lipid-lowering drugs.

\section{Methods}

\subsection{Patients}

The study includes 163 GSDla patients, referred to the Pediatric Department of Peking Union Medical College Hospital between July 1985 and April 2017. Most patients were followed-up once a year. All the patients presented with development retardation, hepatomegaly, fasting hypoglycemia, hyperlipidemia, hyperlactacidemia, and elevated liver enzymes. The diagnosis was confirmed when a mutation was found in the G6PC gene. Dietary control and raw cornstarch treatment were used to maintain normal blood glucose and lipid levels. General guidelines for dosing raw cornstarch included $1.6 \mathrm{~g}$ of raw cornstarch per kilogram of body weight (ideal body weight) every 3-4 hours for young children, and $1.7-2.5 \mathrm{~g}$ raw cornstarch/kg every $4-5$ hours (sometimes 6 hours) for older children, adolescents, and adults. Some patients with severe hyperlipidemia were treated with lipid-lowering drugs. Thirty of the study participants regularly took atorvastatin or fibrates (fenofibrate or gemfibrozil) for more than one year. They were divided into an atorvastatin group and a fibrates group. According to the diagnostic criteria of hyperlipidemia in the American National Cholesterol Education Program (NCEP) Children's Experts Group[8], the data were divided into five age groups: 0-4 y, 5-9 y, 10-14 y, 15-19 y, and greater than 20 years old. 
The participants' mean values for each age group were used as the outcome. The change in the patients' lipid value is relatively fast and becomes stable several months after initiation of treatment. Therefore, each patient was counted as one case in each age group. This can be considered as reflecting on the level of the last one or two years. We focused on the control level of each age group, so the data of any patient in the different age groups are independent of each other.

\subsection{General Examination}

Trained examiners used standardized protocols. All participants were instructed to fast for five hours before venipuncture. Compliance was determined by an interview on the morning of the examination. Laboratory evaluations for all patients included TC, TG, HDL-C, and LDL-C.

\subsection{Diagnostic criteria of hyperlipidemia}

Lipid levels were related to age and sex, and were assessed following the American NCEP Children's Expert Group guidelines. The blood lipid levels were grouped by age, as indicated above. The normal range of TC, TG, HDL-C, and LDL-C in our study was based on previously reported values [8]. For patients older than 18 years, the diagnostic criteria followed the 2016 Chinese Guideline for the Management of Dyslipidemia in Adults[9].

The normal ranges for TC, TG, LDL-C and HDL-C are presented in Table 1.

Table 1

The classification standard of TC, TG, LDL-C and HDL-C in patients of all ages in this study

\begin{tabular}{|c|c|c|c|c|c|c|c|c|c|}
\hline \multirow[b]{2}{*}{ Age(year-old) } & \multirow[b]{2}{*}{ Sex } & \multicolumn{4}{|c|}{$\mathrm{TC}[\mathrm{mg} / \mathrm{dl}(\mathrm{mmol} / \mathrm{L})]$} & \multicolumn{4}{|c|}{$\mathrm{TG}[\mathrm{mg} / \mathrm{dl}(\mathrm{mmol} / \mathrm{L})]$} \\
\hline & & $0-4$ & $5-9$ & $10-14$ & $15-19$ & $>20$ & $0-4$ & $5-9$ & $10-14$ \\
\hline \multirow[t]{2}{*}{$\begin{array}{l}\text { Appropriate } \\
\text { level }\end{array}$} & M & $<176(4.56)$ & $<$ & $\begin{array}{l}< \\
178(4.61)\end{array}$ & $<170(4.40)$ & \multirow{2}{*}{$\begin{array}{l}<200 \\
(5.20)\end{array}$} & $<69(0.78)$ & $<67(0.76)$ & $<80(0$. \\
\hline & $\mathrm{F}$ & $<177(4.58)$ & $\begin{array}{l}< \\
184(4.77)\end{array}$ & $\begin{array}{l}< \\
179(4.64)\end{array}$ & $<177(4.58)$ & & $<79(0.89)$ & $<73(0.82)$ & $<93(1$. \\
\hline \multirow{2}{*}{$\begin{array}{l}\text { Critical high } \\
\text { level }\end{array}$} & M & $177 \rrbracket 209$ & $181 \rrbracket 209$ & $179 \llbracket 208$ & $171 \rrbracket 203$ & \multirow[t]{2}{*}{$200 \rrbracket 240$} & $69 \llbracket 102$ & $67 \bigotimes 104$ & $80 \otimes 12^{\prime}$ \\
\hline & $\mathrm{F}$ & $178 \llbracket 206$ & $185 \llbracket 211$ & $180 \rrbracket 207$ & $178 \llbracket 209$ & & $79 \llbracket 115$ & $73 \bowtie 108$ & $93 \otimes 13 !$ \\
\hline \multirow[t]{2}{*}{ Hyperlipidemia } & M & $>209(5.41)$ & 209(5.41) & 208(5.39) & $>203(5.26)$ & \multirow{2}{*}{$\begin{array}{l}\geq 240 \\
(6.20)\end{array}$} & $>102(1.15)$ & $>104(1.18)$ & $>129$ \\
\hline & $\mathrm{F}$ & $>206(5.34)$ & 211(5.46) & 207(5.36) & $>209(5.41)$ & & $>115(1.30)$ & > 108(1.22) & $>135$ \\
\hline & & \multicolumn{4}{|c|}{ LDL-C[mg/dl(mmol/L)] } & & \multicolumn{3}{|c|}{$\mathrm{HDL}-\mathrm{C}[\mathrm{mg} / \mathrm{dl}(\mathrm{mmol} / \mathrm{L})]$} \\
\hline Age(year-old) & Sex & $5-9$ & $10-14$ & $15-19$ & & $>20$ & $5-9$ & $10-14$ & $15-19$ \\
\hline \multirow[t]{2}{*}{$\begin{array}{l}\text { Appropriate } \\
\text { level }\end{array}$} & M & $\begin{array}{l}< \\
106(2.75)\end{array}$ & $<112(2.90)$ & \multicolumn{2}{|c|}{$<112(2.90)$} & \multirow[t]{2}{*}{$<130(3.40)$} & $>50(1.30)$ & $>47(1.22)$ & $>40(1.04)$ \\
\hline & $\mathrm{F}$ & $\begin{array}{l}< \\
118(3.06)\end{array}$ & $<113(2.93)$ & \multicolumn{2}{|c|}{$<114(2.95)$} & & $>48(1.24)$ & $>46(1.19)$ & $>44(1.14)$ \\
\hline Critical high & M & 106ه133 & $112 \bigotimes 136$ & $112 \otimes 13$ & & $130 \otimes 160$ & $39 \sim 50$ & $38 \sim 47$ & $31 \sim 40$ \\
\hline & $\mathrm{F}$ & 118囚144 & $113 \bigotimes 140$ & $114 \otimes 1$ & & & $37 \sim 48$ & $38 \sim 46$ & $36 \sim 44$ \\
\hline Hyperlipidemia & M & 133(3.44) & > 136(3.52) & $>134(3$ & 47) & $\geq 160(4.10)$ & $<39(1.01)$ & $<38(0.98)$ & $<31(0.80)$ \\
\hline & $\mathrm{F}$ & $\begin{array}{l}> \\
144(3.73)\end{array}$ & > 140(3.63) & $>141$ & 65) & & $<37(0.96)$ & $<38(0.98)$ & $<36(0.93)$ \\
\hline
\end{tabular}

The normal range of TC, TG, LDL-C and HDL-C in children are reference The NCEP Children's Experts Group in the United States

The normal range of TC, TG, LDL-C and HDL-C in patients aged 18 or over are reference 2016 Chinese guideline for the management of dyslipidemia in adult:

In this article, we want to set a cut-off point for severe hypertriglyceridemia. Acute pancreatitis is the main complication of hyperlipidemia. In the glycogen storage disease (GSD) medical guidelines published by the American College of Medical Sciences in 2014, it was suggested that pancreatitis might occur in GSD patients with TG higher than $11 \mathrm{mmol} / \mathrm{L}$. Therefore, TG $\geq 11 \mathrm{mmol} / \mathrm{L}$ was considered as a cut-off point for severe hypertriglyceridemia[7].

\subsection{Statistical methods}

All data were divided into six groups by age: $0-1,2-4,5-9,10-14,15-19$ and greater than 20 years. The data were analyzed with SPSS 24.0 .0 .0 . Means and standard deviations were used to describe normally distributed quantitative variables. Medians and quartile ranges were used to describe nonnormally distributed quantitative variables. To avoid bias, each subject was weighted equally within every age group, the lipid levels of each patient in each age group were average numbers of multiple follow-up data.

Since the difference values were non-normally distributed, the lipids' levels before and after treatment were analyzed by Wilcoxon-ranktest. We analyzed the correlations between TC and TG bv Pearson correlations. The liner regression relationship equation of TC with TG was computed using SPSS program. A $P$ Loading [MathJax]/jax/output/CommonHTML/fonts/TeX/fontdata.js 
value $<0.05$ was considered to be significant in all instances.

\section{Results}

\subsection{General Information}

A total of 163 GSDla patients from 160 families were enrolled in this study. These included 98 males and 65 females, with a male to female ratio of 1:0.66. All the patients were from China. The age of first visit to the hospital between four months and 38 years (mean $8.1 \pm 7.2$ years). The follow-up time was $0-$ 29 years (mean $5.7 \pm 5.4$ years). The age at the last follow-up visit was between four months and 43 years (mean $13.8 \pm 8.2$ years). All patients were treated with raw cornstarch. Lipid levels were assessed 773 times, of which the assessment was performed after the intervention 624 times. TG level was within the normal range in only 13 assessments performed on samples from ten patients(2\%). Patients with severe hyperlipidemia were treated with lipid-lowering drugs. Thirty patients regularly took atorvastatin or fibrates (fenofibrate or gemfibrozil) for more than one year. Lipid levels were assessed a total of 109 times after treatment by atorvastatin or fibrates. Fifteen patients took statins, and fifteen patients took fibrates.

\subsection{Lipid levels of GSDla patients before treatment with lipid-lowering drugs}

The lipid levels of GSDla patients before the intervention and after the raw cornstarch treatment could be seen in Table 2. The mean level of TC, TG, HDL-C and LDL-C and the rate of normal level were listed in the Table 2.

Table 2

The lipid levels of GSDla patients before the intervention and after the raw cornstarch treatment

\begin{tabular}{|lccll|}
\hline \multicolumn{4}{|c|}{ Lipid levels of GSDla patients before the intervention } & \\
\hline & The mean level $(\mathrm{mmol} / \mathrm{L})$ & range $(\mathrm{mmol} / \mathrm{L})$ & The rate of normal level & $\mathrm{n}$ \\
\hline TC & $5.78 \pm 3.07$ & $2.78 \sim 18.77$ & $41.7 \%$ & 133 \\
\hline TG & $8.32 \pm 8.51$ & $1.81 \sim 73.96$ & $1.4 \%$ & 142 \\
\hline HDL-C & $0.92 \pm 0.59$ & $0.29 \sim 5.39$ & $42.4 \%$ & 92 \\
\hline LDL-C & $2.42 \pm 1.36$ & $0.26 \sim 6.26$ & $88.9 \%$ & 92 \\
\hline Lipid levels of GSDla patients after the raw cornstarch treatment & \\
\hline TC & $5.84 \pm 2.18$ & $1.71 \sim 22.79$ & $41.9 \%$ & 289 \\
\hline TG & $5.83 \pm 5.63$ & $0.57 \sim 34.32$ & $2.0 \%$ & 293 \\
\hline HDL-C & $1.03 \pm 0.30$ & $0.24 \sim 2.28$ & $57.7 \%$ & 253 \\
\hline LDL-C & $3.19 \pm 1.14$ & $0.80 \sim 7.32$ & $68 \%$ & 253 \\
\hline
\end{tabular}

\subsection{Lipid levels of GSDla patients after treatment with lipid-lowering drugs}

Fifteen patients were treated with fibrates for $1-3$ years and 15 were treated with atorvastatin for $1-6$ years. TC, TG, HDL-C, and LDL-C levels after treatment with fibrates or atorvastatin were listed in Table 3.

Table 3

The lipid levels of GSDla patients after

treatment with fibrates or atorvastatin

\begin{tabular}{|llll|}
\hline & fibrates & atorvastatin & $\mathbf{n}$ \\
\hline TC & $6.27 \pm 2.64$ & $4.87 \pm 1.41$ & 15 \\
\hline TG & $6.33 \pm 6.04$ & $5.05 \pm 5.50$ & 15 \\
HDL-C & $0.87 \pm 0.55$ & $1.01 \pm 0.27$ & 9 \\
\hline LDL-C & $3.54 \pm 2.48$ & $2.69 \pm 1.03$ & 9 \\
\hline
\end{tabular}

\subsection{Comparison of lipid levels between the different treatments}

\subsubsection{Comparison of lipid levels before and after raw cornstarch treatment}

The lipid levels of patients before and after raw cornstarch treatment are shown in Table 4. After treatment with raw cornstarch, TG level has significantly decreased by $30 \pm 50 \%(P<0.001)$. There was no change in TC level. 
Table 4

The comparison of blood lipids levels before and after raw cornstarch treatment $(\mathrm{M} \pm \mathrm{Q})$

\begin{tabular}{|llllll|}
\hline Index & Number of patients & before treatment & after treatment & Decrease ratio(before treatment-after treatment) & P value \\
\hline TC(mmol/L) & 97 & $5.92 \pm 2.98$ & $5.82 \pm 1.97$ & $0 \pm 30 \%$ & 0.39 \\
\hline $\mathrm{TG}(\mathrm{mmol} / \mathrm{L})$ & 101 & $8.37 \pm 7.23$ & $5.39 \pm 5.29$ & $30 \pm 50 \%$ & $<0.01$ \\
\hline $\mathrm{HDL}-\mathrm{C}(\mathrm{mmol} / \mathrm{L})$ & 65 & $0.96 \pm 0.63$ & $1.10 \pm 0.34$ & $-6 \pm 49 \backslash \%$ & 0.32 \\
\hline $\mathrm{LDL}-\mathrm{C}(\mathrm{mmol} / \mathrm{L})$ & 64 & $2.40 \pm 1.36$ & $2.96 \pm 1.38$ & $-21 \pm 54 \%$ & $<0.01$ \\
\hline
\end{tabular}

The mean values of blood lipids and lipoproteins before and after raw cornstarch treatment were non-normal distribution, and the rank sum test was performed.

\subsubsection{Comparison of lipid levels before and after lipid-lowering drugs treatment}

The blood lipid levels of patients before and after treatment with fibrates are shown in Table 5 , and those after treatment with atorvastatin are shown in Table 6. TC and TG levels have slightly but insignificantly decreased after fibrates treatment. TC in 5/15 patients (33.3\%) and TG in 1/15 patients (6.7\%) have returned to the normal level after treatment with fibrates.

Table 5

The comparison of blood lipids levels before and after fibrates treatment $(M \pm Q)$

\begin{tabular}{|c|c|c|c|c|c|}
\hline Index & Number of patients & raw cornstarch & fibrates & Decrease ratio(raw comstarch -drug) & $P$ value \\
\hline $\mathrm{TC}(\mathrm{mmol} / \mathrm{L})$ & 15 & $6.66 \pm 3.65$ & $6.27 \pm 2.64$ & $-6 \pm 48 \%$ & 0.36 \\
\hline $\mathrm{TG}(\mathrm{mmol} / \mathrm{L})$ & 15 & $7.96 \pm 6.60$ & $6.33 \pm 6.04$ & $21 \pm 101 \%$ & 0.41 \\
\hline $\mathrm{HDL}-\mathrm{C}(\mathrm{mmol} / \mathrm{L})$ & 8 & $0.95 \pm 0.23$ & $0.87 \pm 0.55$ & $10 \pm 17 \%$ & 0.14 \\
\hline LDL-C(mmol/L) & 8 & $2.39 \pm 1.66$ & $3.54 \pm 2.48$ & $-30 \pm 83 \%$ & 0.07 \\
\hline
\end{tabular}

Table 6

The comparison of blood lipids levels before and after atorvastatin treatment $(\mathrm{M} \pm \mathrm{Q})$

\begin{tabular}{|lllll|}
\hline Index & Number of patients & raw cornstarch & atorvastatin & Decrease ratio(raw cornstarch -drug) \\
\hline $\mathrm{TC}(\mathrm{mmol} / \mathrm{L})$ & 15 & $6.96 \pm 1.61$ & $4.87 \pm 1.41$ & $35 \pm 26 \backslash \%$ \\
\hline $\mathrm{TG}(\mathrm{mmol} / \mathrm{L})$ & 15 & $8.80 \pm 5.37$ & $5.05 \pm 5.50$ & $33 \pm 48 \%$ \\
\hline $\mathrm{HDL}-\mathrm{C}(\mathrm{mmol} / \mathrm{L})$ & 9 & $0.96 \pm 0.27$ & $1.01 \pm 0.27$ & $3 \pm 26 \%$ \\
\hline $\mathrm{LDL}-\mathrm{C}(\mathrm{mmol} / \mathrm{L})$ & 9 & $3.42 \pm 1.42$ & $2.69 \pm 1.03$ & $40 \pm 32 \%$ \\
\hline $\begin{array}{l}\text { The mean values of blood lipids and lipoproteins before and after atorvastatin treatment were non-normal distribution, and the rank sum test was } \\
\text { performed. }\end{array}$
\end{tabular}

After treatment with atorvastatin, TC, TG, and LDL-C have all significantly improved $(P<0.05)$. The TC level in $11 / 15$ patients $(73.3 \%)$ returned to normal. The TG level did not return to normal in any of the patients.

\subsection{Linear correlation analysis between TC and TG}

In our study, the TC and TG data were collected in patients with dietary control combined with raw cornstarch treatment. Pearson's correlation coefficient test was performed on the TC and TG levels. The results are shown in Table 7. The TC and TG were found to be positively correlated, with $r=0.514$ and $P<0.001$.

Table 7

The linear correlation analysis between TG and TC

\begin{tabular}{|ll|}
\hline & TG and TC \\
\hline Number of detections & 452 \\
\hline Pearson correlation & 0.514 \\
\hline P value & $<0.001$ \\
\hline
\end{tabular}

\subsection{The linear regression equation associating TC with TG}

It was previously reported that there is a correlation between TC and TG[10]. A multiple linear regression equation for TC and TG had been established for some diseases[11]. 
A total of 452 data points of TC and TG levels were collected in patients with dietary control combined with raw cornstarch treatment. A regression equation was established for TC and TG, and the regression standard error $S_{Y}$ was recorded. The $95 \%$ predicted interval for TC level is represented by $Y \pm t_{0.05 / 2 \text {, }}$ $(452-2) S_{Y}$. Based on this, the regression equation is $Y=1.63 X-2.86$, where $Y$ represents TG level, and $X$ represents TC level in mmol/L. The $F-$ regression test was performed on the overall regression coefficient, resulting in $P<0.01$; the decision coefficient was $\mathrm{R}^{2}=0.264$ and the standard error $\mathrm{S}_{\mathrm{Y}}=4.48(\mathrm{Table} 8$ ).

Table 8 TC and TG linear relationship $₫ n=452, R^{2}=0.264, p<0.01 \otimes T h e$ size of the scatter block represents the number of cases

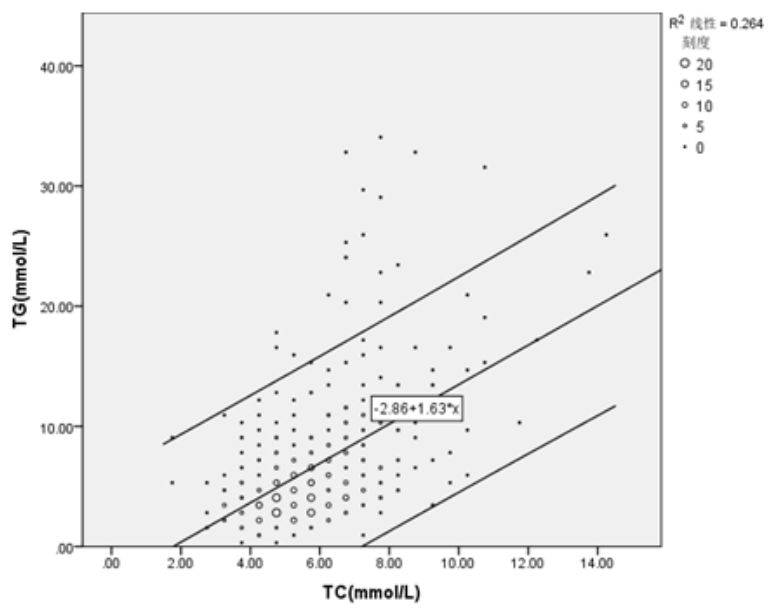

\section{Discussion}

GSDIa is a hereditary disease, caused by G6Pase catalytic subunit defected. The typical manifestation of this metabolic disorder includes hypoglycemia, hyperlipemia, hyperuricemia, and hyperlactacidemia. Blood lipid characteristics of GSDla are high TC, TG, and LDL-C, and low HDL-C. Hyperlipemia is an important risk factor of cardiovascular and cerebrovascular diseases.

Hyperlipidemia in GSDla patients is caused mainly by increased levels of acetyl-CoA and VLDL[12]. Previous studies lack large epidemiological data on blood lipid levels in patients with GSDla. Furthermore, there is no large-scale study on serum lipid levels after using lipid-lowering drugs in GSDla patients.

\subsection{Lipid levels in GSDla patients before intervention}

The TC and TG levels in normal newborns are $1.7 \mathrm{mmol} / \mathrm{L}$ and $0.4 \mathrm{mmol} / \mathrm{L}$, respectively. They both increase gradually after birth and remain at about $4.3 \mathrm{mmol} / \mathrm{L}$ from the age of about two years [13]. The normal value of blood lipid levels varies with age. The normal range values of TC, TG, HDL-C, and LDL-C in this study were based on the American NCEP Children's Expert Group report.

The mean level of TC in our study was $5.78 \pm 3.07 \mathrm{mmol} / \mathrm{L}$ in $133 \mathrm{GSDla}$ patients, with $58.3 \%$ of them having hypercholesteremia. The mean level of TG was $8.32 \pm 8.51 \mathrm{mmol} / \mathrm{L}$ in $142 \mathrm{GSDla}$ patients, with $98.6 \%$ of them having hypertriglyceridemia.

The incidence of hyperlipidemia is high in GSDla patients. A previous study on 62 GSDI patients(53 GSDla and nine GSDIb) showed that the mean levels of TC and TG were $6.18 \pm 2.47 \mathrm{mmol} / \mathrm{L}$ and $11.17 \pm 9.85 \mathrm{mmol} / \mathrm{L}$, respectively, before treatment[14]. Another study, on $11 \mathrm{GSDla}$ patients, found the levels of TC and TG to range between $4.31-6.89 \mathrm{mmol} / \mathrm{L}$ and $16.26-69.09 \mathrm{mmol} / \mathrm{L}$, respectively. However, the incidence of hyperlipemia was not reported in this study [15].

Thus, the level of hyperlipemia before treatment in our study is similar to what was previously reported. The incidence of hypertriglyceridemia is obviously higher than that of hypercholesteremia.

\subsection{Lipid levels in GSDla patient after raw cornstarch treatment}

After raw cornstarch treatment in our study, $58.1 \%$ had hypercholesterolemia, and $98 \%$ had hypertriglyceridemia. It shows that the incidence of hypercholesterolemia and hypertriglyceridemia are still high, even after raw cornstarch treatment.

In the ESGSDI study, $41.3 \%$ of 233 GSDla patients had hypercholesterolemia, and72.7\% had hypertriglyceridemia[2]. Two other studies, on 37 and 41 GSDIa patients, respectively, found the incidence of hypercholesterolemia to range between 76 and $81.6 \%$ and the incidence of hypertriglyceridemia to range between 85.3 and $100 \%[16,17]$. As in our study, the incidence of hypertriglyceridemia was higher than that of hypercholesterolemia.

In a previous study, TC and TG have significantly decreased after raw cornstarch treatment in 62 GSDI patients(including 53 GSDla patients)[14]. TC had decreased from $6.18 \pm 2.47 \mathrm{mmol} / \mathrm{L}$ to $5.61 \pm 1.84 \mathrm{mmol} / \mathrm{L}(P=0.02)$ and TG had decreased from $11.17 \pm 9.85 \mathrm{mmol} / \mathrm{L}$ to $6.81 \pm 5.97 \mathrm{mmol} / \mathrm{L}(P=0.01)$. In another study on 19 GSDI patients treated with nocturnal gastric tube infusion since they were one year old, lipid level decreased significantly but did not return to normal level[18].

In our study, after treatment with raw cornstarch, TG level had significantly decreased by $30 \pm 50 \%(P<0.05)$, while TC level did not change. Similar to the previnus research our studv found that TG level could he decreased significantly by raw cornstarch treatment.

Loading [MathJax]/jax/output/CommonHTML/fonts/TeX/fontdata.js 


\subsection{Comparison of lipid levels after treatment with lipid-lowering drugs}

The lipid-lowering drugs used in this study were fibrates(fenofibrate and gemfibrozil) and atorvastatin. Previous studies had shown that secretion of very-lowdensity lipoprotein (VLDL) was normal, but its degradation rate had decreased in two GSDla patients. This might reflect a decrease in LPL activity. In these two patients, TG had decreased by $50 \%$ following treatment with fibrates[19].

Previous studies showed that dyslipidemia in GSDla patients is characterized by an increased level of VLDL and decreased LDLR metabolism. Furthermore, statins had been shown to have strong effects on lipid-lowering treatment in multiple studies, mainly on lowering VLDL remnants through the uptake of the LDL receptors. Thus, lipid levels can be substantially decreased by statins [20].

This study analyzed lipid metabolism in $30 \mathrm{GSDla}$ patients. The levels of TC and TG have improved after fibrates treatment, but changes did not reach the statistical significance level. TC and TG levels, however, could be significantly improved by atorvastatin treatment. TC in 11/15 patients(73.3\%) has decreased back to a normal level. It is suggested that lipid metabolism could be improved following treatment with lipid-lowering drugs. We found that the therapeutic effect of atorvastatin was better than that of fibrates.TC could achieve a normal level in most patients following dietary control and treatment with raw cornstarch and atorvastatin.

\subsection{The linear regression equation between TC and TG, and blood lipid control target}

Pearson's correlation test suggested that there is a positive correlation between TC and TG. TC and TG were found to be related at medium intensity. A regression equation was established for this relationship, $\mathrm{TG}=1.63 \mathrm{TC}-2.86$. The F-regression test was performed on the overall regression coefficient, showing a high significance level $(P<0.01)$, with the decision coefficient being $\mathrm{R}^{2}=0.264$.

The 2014 GSDI guidelines, published by the Genetics Society of the American Medical College, recommend maintaining a normal blood lipids range to reduce the risk of arteriosclerotic cardiovascular disease(ASCVD) and pancreatitis[7]. However, previous studies have shown that hyperlipidemia could be improved but not cured in GSDI patients[16]. The incidence rate of hypertriglyceridemia is obviously higher than that of hypercholesteremia, but the incidence of pancreatitis, the main complication of hypertriglyceridemia, is low. It is important to decrease the level of TC as it is considered a key factor leading to ASCVD [21]. After treatment with lipid-lowering drugs, TC has decreased to normal in most patients, but it was difficult to decrease TG to a normal level.

Because the complications of hyperlipidemia are caused mainly by TC, therefore, the TC level is the main target of lipid control in GSD patients. If TC is maintained at a normal level, TG do not have to be maintained normal and a certain degree of hypertriglyceridemia could be accepted. There is no need to further increase the dose of lipid-lowering drugs. Thereby, as long as the TC remains normal, we could set a TG target to allow a certain degree of hypertriglyceridemia. The lower bound of Chinese children's TC normal level (5.18 mmol/L[22]) was inserted into the established regression equation to obtain $\mathrm{TG}=5.58 \mathrm{mmol} / \mathrm{L}$. The prediction interval at 95\% confidence level was $-3.28 \sim 14.37 \mathrm{mmol} / \mathrm{L}$. We, therefore, targeted to keep TG level below $5.58 \mathrm{mmol} / \mathrm{L}$. When this was achieved, a normal TC level could be maintained with no need for a further increase in lipid-lowering drug dosage.

Many studies had shown that it is difficult to control normal lipid levels in GSDla patients. The aim is to maintain TC at a normal level while allowing a certain degree of hypertriglyceridemia. As long as TC could be maintained at a normal level, the TG level derived from this regression equation could be used as a reference for clinical treatment. Moreover, this was a retrospective study. A long follow-ups time is needed to observe differences in atherosclerosis incidence between patients with $T G \varangle 5.58 \mathrm{mmol} / \mathrm{L}$ and $T G \leq 5.58 \mathrm{mmol} / \mathrm{L}$. Long-term treatment research is needed to confirm the feasibility of this control target.

The blood lipid levels in the NCEP standard are grouped by age. If we insert the normal values of TC in the different age groups into the regression equation, we could get their respective acceptable hypertriglyceridemia levels for different ages period.

\section{Conclusion}

Patients with GSDla have significant abnormalities in lipid metabolism. We find that there is a linear correlation between TC and TG, described as TG=-2.86 + $1.63^{\star} \mathrm{TC}$. We suggest that if the TC can be maintained at a normal level, a certain degree of hypertriglyceridemia can be accepted. We also suggest that the aim should be to keep the TG level lower than $5.58 \mathrm{mmol} / \mathrm{L}$ after treatment. A normal TC level could be maintained with no need for a further increase in lipidlowering drug dosage. This study finds that lipid metabolism can be improved by lipid-lowering drugs, with the therapeutic effect of atorvastatin being better than that of fibrates.

\section{List Of Abbreviations}

Glycogen storage disease type la(GSDla)

Total cholesterol(TC)

Total triglycerides(TG)

Low density lipoprotein-cholesterol(LDL-C)

High density lipoprotein-cholesterol(HDL-C)

Glucose-6-phosphatase (G6Pase)

Loading [MathJax]/jax/output/CommonHTML/fonts/TeX/fontdata.js 


\section{Declarations}

\section{- Ethics approval and consent to participate[}

Because of the retrospective nature of the study, the ethics approval and consent to participate is not needed in this study. We will do our best to protect patients' privacy.

\section{- Consent for publication}

Not applicable

\section{- Competing interests}

The authors disclose no conflicts.

\section{- Funding}

This work was supported by the National Key Research and Development Program of China Grant No. 2016YFC0905102; National Key Research and Development Program of China Grant No. 2016YFC0901500.

\section{- Authors' contributions}

Zhenjie Zhang (Formal analysis; Investigation; Methodology; Writing- original draft)

Yuheng Yuan (Data curation; Formal analysis)

Mingsheng Ma (Conceptualization; Investigation; Resources)

Yuehui Hong (Data curation; Formal analysis; Investigation)

Zhixing Sun (Software; Supervision; Validation)

Yiwen Xu (Investigation; Methodology; Project administration)

Zhengqing Qiu (Funding acquisition; Writing - review \& editing)

\section{- Acknowledgements}

The authors will thank all the patients for great help in the artical.

\section{- Availability of data and materials}

All data generated or analysed during this study are included in this published article

\section{References}

1. Chou JY, Jun HS, Mansfield BC. Glycogen storage disease type I and G6Pase-beta deficiency: etiology and therapy. NAT REV ENDOCRINOL. 2010;6(12):676-88.

2. Rake J, Visser G, Labrune P, Leonard J, Ullrich K, Smit P. Glycogen storage disease type I: diagnosis, management, clinical course and outcome. Results of the European Study on Glycogen Storage Disease Type I (ESGSD I). EUR J PEDIATR. 2002;161:20-34.

3. Chou JY, Matern D, Mansfield BC, Chen YT. Type I glycogen storage diseases: disorders of the glucose-6-phosphatase complex. CURR MOL MED. 2002;2(2):121-43.

4. Rajas F, Bruni N, Montano S, Zitoun C, Mithieux G. The glucose- 6 phosphatase gene is expressed in human and rat small intestine: regulation of expression in fasted and diabetic rats. GASTROENTEROLOGY. 1999;117(1):132-9.

5. Pan CJ, Lin B, Chou JY. Transmembrane topology of human glucose 6-phosphate transporter. J BIOL CHEM. 1999;274(20):13865-9.

6. Yang CJ, Mansfield BC. Molecular Genetics of Type 1 Glycogen Storage Diseases. Trends Endocrinol Metab. 1999;10(3):104-13.

7. Kishnani PS, Austin SL, Abdenur JE, Arn P, Bali DS, Boney A, Chung WK, Dagli Al, Dale D, Koeberl D, et al: Diagnosis and management of glycogen storage disease type I: a practice guideline of the American College of Medical Genetics and Genomics. GENET MED 2014.

8. Third Report of the National Cholesterol Education Program (NCEP). Expert Panel on Detection, Evaluation, and Treatment of High Blood Cholesterol in Adults (Adult Treatment Panel III) final report. CIRCULATION. 2002;106(25):3143-421.

9. [2016 Chinese guideline for the management of dyslipidemia in adults]. Zhonghua Xin Xue Guan Bing Za Zhi 2016, 44(10):833-853.

10. Fan P, Liu B. [Correlation analysis of lipids and apolipoproteins in plasma HDL, LDL and VLDL of normal subjects and endogenous hypertriglyceridemics]. Hua Xi Yi Ke Da Xue Xue Bao. 1995:26(2):141-5.

Loading [MathJax]/jax/output/CommonHTML/fonts/TeX/fontdata.js 
11. Ma J, Yu J, Hao G, Wang D, Sun Y, Lu J, Cao H, Lin F. Assessment of triglyceride and cholesterol in overweight people based on multiple linear regression and artificial intelligence model. LIPIDS HEALTH DIS. 2017;16(1):42.

12. Carvalho PMS, Silva NJMM, Dias PGD, Porto JFC, Santos LC, Costa JMN. Glycogen Storage Disease type 1a - a secondary cause for hyperlipidemia: report of five cases. Journal of Diabetes Metabolic Disorders. 2013;12(1):25.

13. Lloyd JK. Hyperlipidaemia in children. Br Heart J. 1975;37(2):105-14.

14. Guo LL, Xu RY, Zhu WL. [Cardiovascular risk profile of patients with glycogen storage disease type I]. Zhonghua Xin Xue Guan Bing Za Zhi. 2011;39(6):508-11.

15. Greene HL, Swift LL, Knapp HR. Hyperlipidemia and fatty acid composition in patients treated for type IA glycogen storage disease. J Pediatr. 1991;119(3):398-403.

16. Smit G. The long-term outcome of patients with glycogen storage disease type la. J Inherit Metab Dis. 1990;1(13):411-8.

17. Talente GM, Coleman RA, Alter C, Baker L, Brown BI. Glycogen storage disease in adults. ANN INTERN MED. 1994;3(120):218.

18. Ublin D, Wendel G, Schwahn U. B: Type I glycogen storage disease: favourable outcome on a strict management regimen avoiding increased lactate production during childhood and adolescence. EUR J PEDIATR. 2002;161:40-5.

19. Wierzbicki AS, Watt GF, Lynas J, Winder AF, Wray R. Very low-density lipoprotein apolipoprotein B-100 turnover in glycogen storage disease type la (von Gierke disease). J INHERIT METAB DIS. 2001;24(5):527-34.

20. Bandsma RH, Prinsen BH, van Der Velden MS, Rake JP, Boer T, Smit GP, Reijngoud DJ, Kuipers F. Increased de novo lipogenesis and delayed conversion of large VLDL into intermediate density lipoprotein particles contribute to hyperlipidemia in glycogen storage disease type 1a. PEDIATR RES. 2008;63(6):702-7.

21. Luirink IK, Wiegman A, Kusters DM, Hof MH, Groothoff JW, de Groot E, Kastelein JJP, Hutten BA. 20-Year Follow-up of Statins in Children with Familial Hypercholesterolemia. The New England Journal of Medicine. 2019;381(16):1547-56.

22. Pediatrics TEBO. Expert consensus on prevention and treatment of dyslipidemia in children and adolescents. CHINESE JOURNAL OF PEDIATRICS. 2019;6(47):426-8. 